\title{
Glypican-3 expression in clear cell adenocarcinoma of the ovary
}

\author{
Daichi Maeda ${ }^{1}$, Satoshi Ota ${ }^{1}$, Yutaka Takazawa ${ }^{1}$, Hiroyuki Aburatani ${ }^{2}$, \\ Shunsuke Nakagawa ${ }^{3}$, Tetsu Yano ${ }^{3}$, Yuji Taketani ${ }^{3}$, Tatsuhiko Kodama ${ }^{4}$ \\ and Masashi Fukayama ${ }^{1}$
}

${ }^{1}$ Department of Pathology, Faculty of Medicine, The University of Tokyo, Tokyo, Japan; ${ }^{2}$ Genome Science Division, Research Center for Advanced Science and Technology, The University of Tokyo, Tokyo, Japan; ${ }^{3}$ Department of Obstetrics and Gynecology, Faculty of Medicine, The University of Tokyo, Tokyo, Japan and ${ }^{4}$ Laboratory for Systems Biology and Medicine, Research Center for Advanced Science and Technology, The University of Tokyo, Tokyo, Japan

\begin{abstract}
Glypican-3 is a heparan sulfate proteoglycan that is overexpressed in various neoplasms such as hepatocellular carcinoma, malignant melanoma, and testicular yolk sac tumor. Glypican-3 is currently regarded as a tumor marker and potential target for immunotherapy. To clarify the significance of glypican-3 expression in ovarian clear cell adenocarcinoma, we evaluated glypican-3 expression by immunohistochemistry in nonneoplastic and neoplastic ovaries, and other Müllerian duct derivatives including endometrium in different menstrual phases. Among the benign lesions examined, glypican-3 expression was identified exclusively in the endometrial epithelium in the gestational period. A total of 213 cases of ovarian adenocarcinoma, including 94 clear cell adenocarcinomas, were studied. Glypican-3 expression was observed in $44 \%$ of clear cell adenocarcinomas, whereas it was rarely observed in other histological subtypes: mucinous (4\%), endometrioid $(5 \%)$, and serous (11\%; $P<0.0001)$. All six ovarian yolk sac tumors showed diffuse immunoreactivity for glypican-3. In cases of clear cell adenocarcinoma, no correlations were found between glypican-3 expression and clinicopathological factors, such as tumor stage, lymph node metastasis, peritoneal dissemination, and death rate. However, glypican-3 expression was significantly associated with poor overall survival in stage III/IV clear cell adenocarcinoma cases. Our results suggest that overexpression of glypican-3 may be related to the development and aggressive behavior of ovarian clear cell adenocarcinoma.
\end{abstract}

Modern Pathology (2009) 22, 824-832; doi:10.1038/modpathol.2009.40; published online 27 March 2009

Keywords: ovarian clear cell adenocarcinoma; glypican-3; yolk sac tumor

Ovarian clear cell adenocarcinoma is a distinct histological subtype of ovarian epithelial carcinoma that occurs more frequently in Japan than in Western countries. ${ }^{1-6}$ Histologically, clear cell adenocarcinoma is characterized by clear cells or hobnail cells growing in papillary, tubulocystic, and solid patterns, ${ }^{7}$ and they show strong resemblance to endometrial glands during pregnancy (Arias-Stella change $)^{8}$ and yolk sac tumors. ${ }^{9}$ Although clear cell adenocarcinomas were initially thought to be of mesonephric origin, it is now widely accepted that these tumors are of Müllerian origin. ${ }^{10}$ In fact, clear cell adenocarcinomas are closely associated with

Correspondence: Dr M Fukayama, MD, PhD, Department of Pathology, Faculty of Medicine, The University of Tokyo, 7-3-1 Hongo Bunkyoku, Tokyo 113-0033, Japan.

E-mail: mfukayama-tky@umin.net

Received 21 November 2008; revised and accepted 23 February 2009; published online 27 March 2009 endometriosis, ${ }^{11,12}$ and sequential changes from endometriosis to clear cell adenocarcinoma have been reported. ${ }^{13}$ Clinically, patients with clear cell adenocarcinoma have a poor prognosis due to the poor response of the tumor to conventional platinum- or taxane-based chemotherapy. ${ }^{5,12,14}$ Therefore, alternative therapeutic options for ovarian clear cell adenocarcinoma are warranted as an additive modality.

Glypican-3 (GPC3) is a cell-surface heparan sulfate proteoglycan that binds to the cell membrane via glycosylphosphatidylinositol anchors. ${ }^{15}$ The gene encoding GPC3 is localized on Xq26, and its product is believed to regulate cellular growth and apoptosis by interacting with a variety of morphogenic or growth factors, such as Wnt, fibroblast growth factor 2, and bone morphogenic protein 7 in a tissue-specific manner. ${ }^{16-18}$ GPC3 expression, ubiquitous in the embryo, is silenced in most adult tissues, ${ }^{19,20}$ and is regarded, therefore, as an 
oncofetal protein. Its overexpression has been reported in certain types of tumors, such as hepatocellular carcinoma, ${ }^{21,22}$ melanoma, ${ }^{23}$ lung squamous cell carcinoma, ${ }^{24}$ and testicular germ cell tumors. ${ }^{25,26}$ GPC3 has also been reported to act as an immunohistochemical and serum marker for hepatocellular carcinoma and malignant melanoma. ${ }^{21,23,27}$ In addition, it is now expected to be a potential target for immunotherapy against these neoplasms. ${ }^{28-30}$

With regard to ovarian carcinoma, there have been only a few studies regarding its GPC3 expression, and their results were inconsistent. In an immunohistochemical study of 251 ovarian cancers using the tissue microarray technique, Stadlmann et $a l^{31}$ reported that GPC3 expression was strongly associated with the clear cell histotype. However, the number of clear cell adenocarcinomas studied was small (11 cases). On the other hand, Esheba et al ${ }^{32}$ reported a higher frequency of GPC3 expression in ovarian yolk sac tumor (98\%) in comparison with clear cell adenocarcinoma (17\%). Their series included 42 clear cell adenocarcinomas and immunohistochemistry was performed mostly on tissue microarray sections. The discrepancy between these immunohistochemical results can be attributed to the small numbers of cases studied and limited areas of tissue evaluated on tissue microarray sections.

In this study, we evaluated GPC3 expression in ovarian carcinomas, especially clear cell adenocarcinomas. To overcome the insufficiency of tissue microarray studies, we applied immunohistochemistry to full tissue sections of a large series of clear cell adenocarcinoma (94 cases) in Japanese patients. Furthermore, as GPC3 expression in benign counterparts of ovarian carcinoma, including various Müllerian duct derivatives, is essential for understanding the significance of GPC3 expression, we assessed GPC3 expression in ovarian surface epithelial inclusions and the following nonneoplastic epithelium of Müllerian duct origin: fallopian tube epithelium, endometrial epithelium at different stages of the menstrual cycle, endometrium during pregnancy, endocervical epithelium, and glands involved in endometriosis.

\section{Materials and methods}

\section{Tissue Samples}

A total of 213 cases of primary ovarian carcinoma were retrieved from the archives of the Department of Pathology of the University of Tokyo Hospital. These included 94 cases of clear cell adenocarcinoma, 25 cases of mucinous adenocarcinoma, 38 cases of endometrioid adenocarcinoma, and 56 cases of serous adenocarcinoma. Hematoxylin and eosin (H\&E)-stained slides of all the cases were reviewed. Histological diagnosis was based on the most recent criteria of the World Health Organization. ${ }^{7}$ Cases diagnosed as ovarian yolk sac tumor of the ovary $(n=4)$ or mixed germ cell tumor with yolk sac tumor components $(n=2)$ were also retrieved from our archives. One of the mixed germ cell tumors was composed of yolk sac tumor and mature cystic teratoma, and the other mixed germ cell tumor was composed of yolk sac tumor and dysgerminoma. In addition, five specimens containing ovarian surface epithelial inclusions and the following sections of nonneoplastic Müllerian duct derivatives were included in the study: fallopian tube epithelium of 6 patients, endometrial epithelium of 43 patients (12 in proliferative phase, 12 in secretory phase, 7 in menstrual phase, and 12 in gestational state), endocervical epithelium of 6 patients, and endometriosis of 8 patients.

\section{Clinical Survey of Patients with Ovarian Clear Cell Adenocarcinoma}

We examined the medical records of 94 clear cell adenocarcinoma patients and their demographics; data including age, tumor site, preoperative diagnosis, and survival time were obtained. None of the patients underwent preoperative chemotherapy or radiotherapy. The correlations of GPC3 expression with the following clinical variables were evaluated: age, stage of carcinoma (stage I/II vs stage III/IV), ovarian bilateralness, peritoneal dissemination, retroperitoneal lymph node metastasis, and death rate. Stage of carcinoma was assessable in 68 cases. Tumor stage could not be determined for 26 cases because of incomplete surgical procedures or missing data. Staging was in accordance with the standards of the International Federation of Gynecology and Obstetrics (FIGO). Ovarian bilateralness could be assessed in 76 cases. Precise evaluation of peritoneal dissemination that included microscopic examination of the omentum was performed in 83 cases. Retroperitoneal lymph node dissection was performed in 74 cases. Follow-up information included overall survival and cancer-related death. Follow-up period was calculated from the date of surgery to the date of death or last clinical evaluation. The mean follow-up interval was 48months (range 1-196 months).

\section{Glypican-3 Immunohistochemical Staining}

All the tissue samples were fixed in formalin and embedded in paraffin. Full tissue sections were used for immunohistochemistry in all cases. Immunohistochemistry was performed with a monoclonal mouse antibody against human GPC3 (1:200, Clone IG12; BioMosaics, Burlington, VT, USA). Immunohistochemical staining was performed according to standard techniques on a Ventana Benchmark ${ }^{\circledR}$ XT autostainer (Ventana Medical Systems Inc., Tucson, AZ, USA). Appropriate positive and negative controls were included. The immunostaining results 
were interpreted as positive when at least $5 \%$ of cells expressed GPC3. Both cytoplasmic and membranous staining were evaluated. The positive expression was further categorized as $1+(5-14 \%)$, $2+(15-49 \%)$, or $3+(\geq 50 \%)$. No expression or expression in less than $5 \%$ of tumor cells was considered negative.

\section{Statistical Analysis}

Statistical analysis was performed using the $\chi^{2}$-test. Overall survival of clear cell adenocarcinoma cases was calculated using the Kaplan-Meier method, and statistical analyses were performed using the logrank test. Statistical analyses were performed with StatView 5.0 software (SAS Institute, Cary, NC, USA) and $P<0.05$ was considered statistically significant.

\section{Results}

\section{GPC3 Expression in Ovarian Surface Epithelial Inclusions and Nonneoplastic Müllerian Duct Derivatives}

Results of GPC3 immunohistochemistry in ovarian surface epithelial inclusions, fallopian tube epithelium, endocervical epithelium, endometrial epithelium at different menstrual phases, and endometriosis are summarized in Table 1. None of the ovarian surface epithelium inclusions showed GPC3 expression $(n=5)$. In the nonneoplastic Müllerian duct derivatives, GPC3 expression was observed almost exclusively in endometrium in the gestational state, which showed Arias-Stella reaction (Figure 1). On the other hand, endometrium in the nonpregnant state was usually negative for GPC3, with one exception among 29 specimens. Finally, GPC3 expression was not observed in any of the epithelia involved in endometriosis.

\section{GPC3 Expression in Ovarian Carcinomas and Yolk Sac Tumors}

The immunohistochemical results are summarized in Table 2. GPC3 expression was evaluated in 213 ovarian carcinomas. Cytoplasmic staining was observed in all the positive cases. Focal membranous staining was identified in approximately $30 \%$ of these positive cases. Among the four histological subtypes of ovarian adenocarcinoma, GPC3 expression was observed predominantly in clear cell adenocarcinomas (44\%). Approximately $10 \%$ of clear cell adenocarcinomas showed diffuse $(3+)$ positivity. In contrast, positive immunoreactivity for GPC3 was rarely observed in other histological subtypes of ovarian adenocarcinoma. GPC3 positivity rates were 4,5 , and $11 \%$ in mucinous, endometrioid, and serous adenocarcinomas, respectively. Diffuse immunostaining was not seen in these non-clear cell histotypes of ovarian carcinoma.

In clear cell adenocarcinoma cases, positive staining was observed in various histological patterns, such as tubulocystic, papillary, solid, and oxyphilic patterns (Figure 2). In some cases, an adenofibromatous component in the clear cell adenocarcinoma showed positive staining for GPC3. There was no significant association between GPC3 immunoreactivity and the predominant histological pattern of clear cell adenocarcinomas. However, a statistically significant correlation was observed between GPC3 immunoreactivity and severity of nuclear atypia (Table 3 ).

All six ovarian yolk sac tumors were positive for GPC3 (Table 2). GPC3 expression was present in more than $50 \%$ of the cells in all cases (Figure 3). Although the predominant histological patterns in all these cases were reticular and microcystic patterns, GPC3 expression was also observed in minor components that showed a solid or glandular pattern of growth.

\section{Correlation of GPC3 Expression with Clinical Characteristics in Ovarian Clear Cell Adenocarcinomas}

As GPC3 expression was observed predominantly in ovarian clear cell adenocarcinomas, we analyzed its correlation with the clinical characteristics (Table 4). There were no significant correlations between GPC3 expression and patient age, tumor stage, ovarian bilateralness, peritoneal dissemination,

Table 1 GPC3 expression in ovarian surface epithelial inclusions and nonneoplastic Müllerian duct derivatives

\begin{tabular}{|c|c|c|c|c|c|c|c|c|}
\hline & OSEI & $\begin{array}{l}\text { Fallopian } \\
\text { tube }\end{array}$ & Endocervix & $\begin{array}{l}\text { Endometrium } \\
\text { (proliferative) }\end{array}$ & $\begin{array}{l}\text { Endometrium } \\
\text { (secretory) }\end{array}$ & $\begin{array}{l}\text { Endometrium } \\
\text { (menstrual) }\end{array}$ & $\begin{array}{l}\text { Endometrium } \\
\text { (gestational) }\end{array}$ & Endometriosis \\
\hline- & 5 & 6 & 6 & 12 & 11 & 7 & 2 & 8 \\
\hline $1+$ & 0 & 0 & 0 & 0 & 1 & 0 & 3 & 0 \\
\hline $2+$ & 0 & 0 & 0 & 0 & 0 & 0 & 5 & 0 \\
\hline $3+$ & 0 & 0 & 0 & 0 & 0 & 0 & 2 & 0 \\
\hline Overall (+) & $0 / 5(0 \%)$ & $0 / 6(0 \%)$ & $0 / 6(0 \%)$ & $0 / 12(0 \%)$ & $1 / 12(8 \%)$ & $0 / 7(0 \%)$ & $10 / 12(83 \%)$ & $0 / 8(0 \%)$ \\
\hline
\end{tabular}

OSEI, ovarian surface epithelial inclusion.

Immunopositivity was assessed as follows: $3+, \geq 50 \%$ of the tumor cells positive; $2+, 15-49 \%$ of the tumor cells positive; +, $5-14 \%$ of the tumor cells positive;,$-<5 \%$ cells positive or no significant staining. 

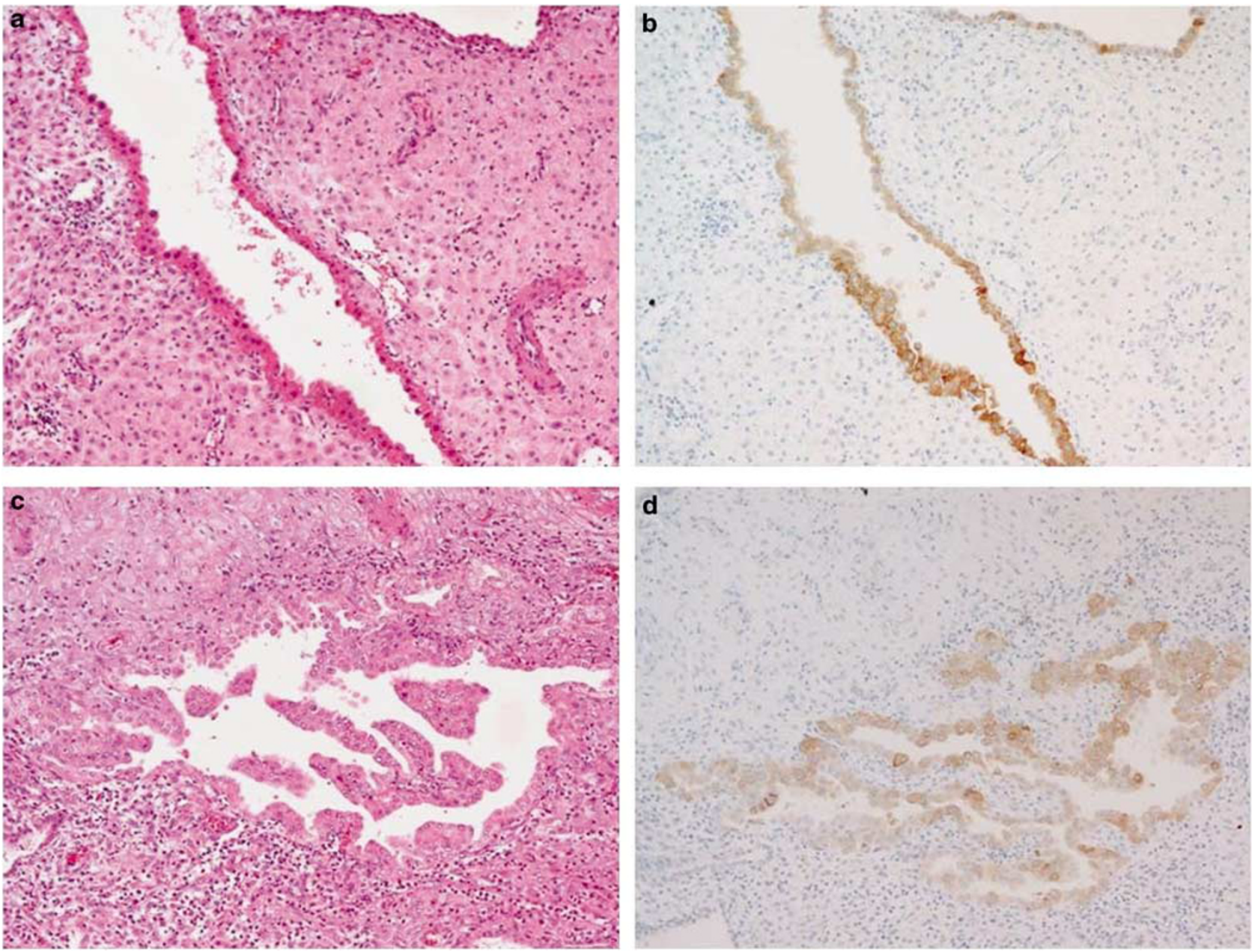

Figure 1 Endometrium in gestational state showing GPC3 immunoreactivity. (a) Endometrial epithelium covering the decidual tissue is composed of cells with hobnail appearance. (b) GPC3 immunoreactivity is observed in the gestational state endometrium. (c) Endometrial epithelium with prominent Arias-Stella reaction and (d) its GPC3 immunoreactivity.

Table 2 GPC3 expression in ovarian carcinomas and yolk sac tumors

\begin{tabular}{lcccccc}
\hline & Clear cell & Mucinous & Endometrioid & Serous & Total (carcinoma) & Yolk sac tumor \\
\hline- & 53 & 24 & 36 & 50 & 163 & 0 \\
$1+$ & 14 & 1 & 0 & 5 & 20 & 0 \\
$2+$ & 18 & 0 & 21 & 9 & 0 \\
$3+$ & 9 & 0 & 0 & 0 & 6 & $6 / 213(23 \%)$ \\
Overall $(+)$ & $41 / 94(44 \%)^{\mathrm{a}}$ & $1 / 25(4 \%)$ & $2 / 38(5 \%)$ & $6 / 56(11 \%)$ & $50 / 6)$ \\
\hline
\end{tabular}

Immunopositivity was assessed as follows: $3+, \geq 50 \%$ of the tumor cells positive; $2+, 15-49 \%$ of the tumor cells positive; +, 5-14\% of the tumor cells positive;,$-<5 \%$ cells positive or no significant staining.

${ }^{a}$ Among the ovarian carcinomas, Glypican-3 expression showed significant association with clear cell histotype $(P<0.0001)$.

lymph node involvement, or death rate. Then, we performed survival analyses in ovarian clear cell adenocarcinomas using the Kaplan-Meier method. First, we assessed the association between tumor stage and overall survival in clear cell adenocarcinoma cases, and our results indicated that stage III/IV cases $(n=20)$ had significantly poor prognoses in comparison with stage I/II cases
( $n=48 ; P<0.0001$; Figure 4). To further investigate the significance of GPC3 expression in ovarian clear cell adenocarcinomas, the correlation between GPC3 expression and overall survival was examined. When all 94 clear cell adenocarcinoma cases were analyzed, regardless of stage, no significant association was observed between GPC3 expression and survival $(P=0.30$; Figure 5a). 

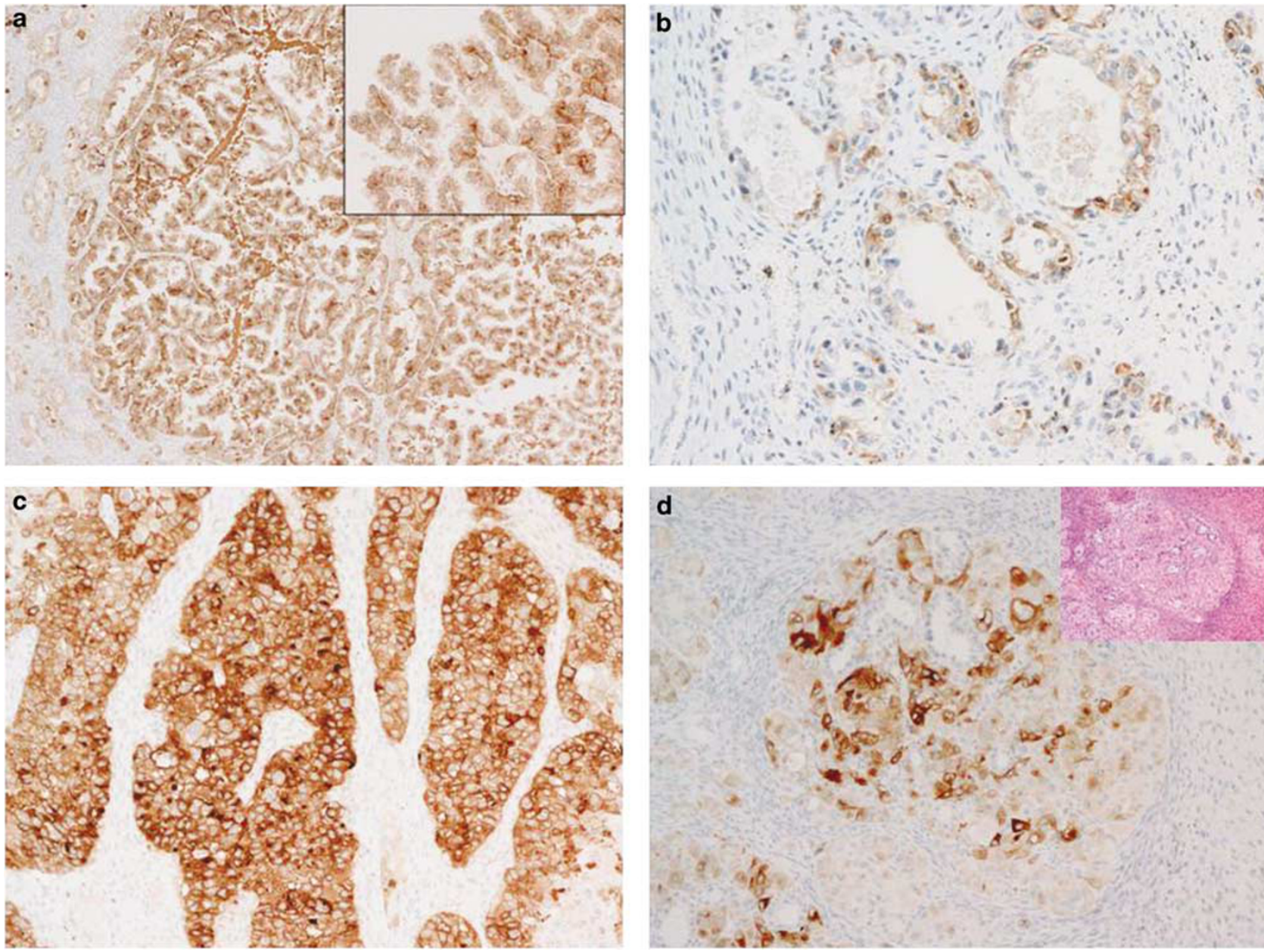

Figure 2 GPC3 expression in ovarian clear cell adenocarcinoma with (a) papillary, (b) tubular, (c) solid, and (d) oxyphilic patterns.

Table 3 Correlation of GPC3 immunopositivity with pathological features in 94 ovarian clear cell carcinoma cases

\begin{tabular}{lrrr}
\hline \multirow{2}{*}{ Pathological features } & \multicolumn{2}{c}{ Glypican-3 } & $\mathrm{P}$ \\
\cline { 2 - 3 } & - & + & \\
\hline Nuclear atypia & & & \\
$\quad$ Mild & 22 & 9 & \\
$\quad$ Moderate & 16 & 8 & \multirow{2}{*}{$0.0075^{\mathrm{a}}$} \\
$\quad$ Severe & 5 & 14 & \\
Predominant histologic pattern & & \\
$\quad$ Tubulocystic & 18 & 28 & \\
$\quad$ Papillary & 12 & 14 & \multirow{2}{*}{0.67} \\
$\quad$ Solid & 11 & 11 & \\
\hline
\end{tabular}

${ }^{\mathrm{a}}$ Statistically significant.

However, in stage III/IV cases, the prognosis of the patients with GPC3-positive clear cell adenocarcinoma was significantly poorer than that of GPC3-negative clear cell adenocarcinoma $(P=0.019$; Figure 5b).

\section{Discussion}

In this study, we have shown that GPC3 is exclusively overexpressed in clear cell adenocarcinoma among ovarian adenocarcinomas. GPC3 was expressed in nearly half $(44 \%)$ of the clear cell adenocarcinomas. Approximately $10 \%$ of the clear cell adenocarcinomas showed diffuse $(3+)$ immunoreactivity. In two previous studies on GPC3 expression in ovarian tumors, a significant discrepancy was observed regarding the GPC3 positivity rate among clear cell adenocarcinomas. ${ }^{31,32}$ Stadlmann et $a l^{31}$ reported that as many as $64 \%$ (7/ 11) of the clear cell adenocarcinomas were GPC3positive, and observed diffuse GPC3 positivity in $55 \%(6 / 11)$ of the clear cell adenocarcinomas. In contrast, Esheba et $a l^{32}$ reported that only $17 \%(7 / 42)$ of the clear cell adenocarcinomas were GPC3-positive, and they observed diffuse immunoreactivity for GPC3 in $7 \%(3 / 42)$ of the cases. We assumed that these discrepancies were due to the relatively small numbers of clear cell adenocarcinoma cases included in these series and the inconsistencies in the 

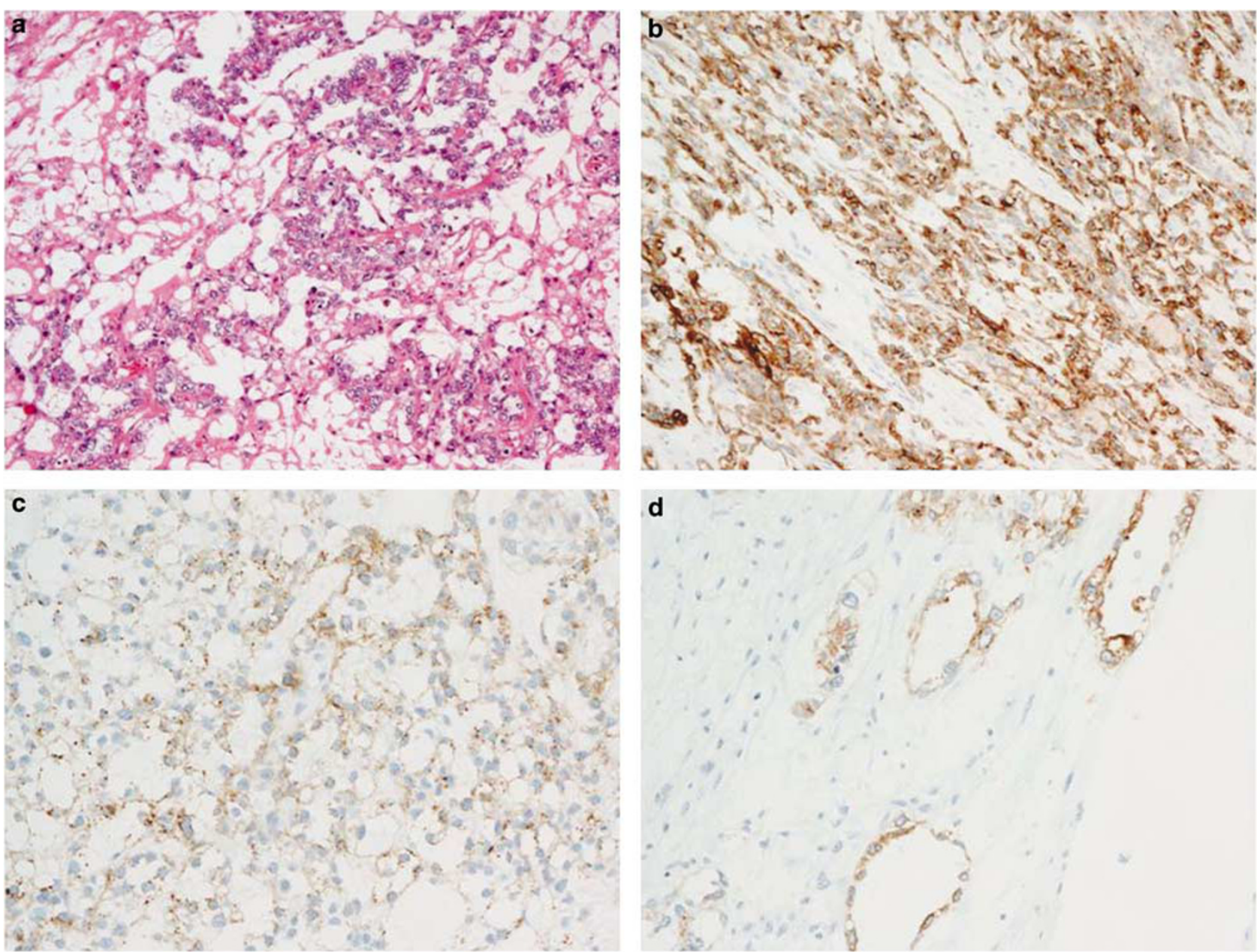

Figure 3 Ovarian yolk sac tumor showing GPC3 expression. (a) Ovarian yolk sac tumor showing reticular pattern of growth. A network of irregular spaces is lined by atypical cells. (b) Diffuse GPC3 positivity observed in a reticular pattern component of yolk sac tumor. (c) Yolk sac tumor with microcystic pattern showing GPC3 expression. (d) Glandular structures are also GPC3-positive.

results obtained by the tissue microarray technique. By performing immunohistochemistry in one of the largest series of ovarian clear cell adenocarcinomas studied to date, and with the use of full tissue sections for immunohistochemistry, we showed that GPC3 is expressed in clear cell adenocarcinomas, and not in non-clear cell subtypes of ovarian carcinoma, such as endometrioid, mucinous, or serous adenocarcinoma. When rare positive GPC3 immunoreactivity was observed in these non-clear cell subtypes, it was usually focal.

Although precursors of ovarian carcinoma are for the most part unknown, ovarian surface epithelium and other Müllerian duct derivatives, such as endometriosis, are established candidates. ${ }^{33}$ The frequent association between endometriosis and ovarian clear cell adenocarcinomas is well known, and endometriosis is now regarded as a precursor of at least some clear cell adenocarcinomas. ${ }^{13}$ In this study, we selected ovarian surface epithelial inclusions, fallopian tube epithelium, endocervical epithelium, endometrial epithelium at different stages of the menstrual cycle, endometrial epithe- lium during pregnancy, and glands involved in endometriosis as benign counterparts of ovarian carcinomas. Then, we investigated their GPC3 expression. Among the nonneoplastic lesions examined, GPC3 expression was identified almost exclusively in the endometrium of the gestational period. A recent study showed that hepatocyte nuclear factor $1 \beta$ (HNF-1 $\beta$ ), another specific marker for clear cell adenocarcinoma, is expressed by gestational state endometrium and mid-late secretory phase endometrium. ${ }^{34}$ The frequent expression of these specific markers of clear cell adenocarcinoma (GPC3 and HNF-1 $\beta$ ) in gestational state endometrium is of great interest when considering the histological similarity between gestational state endometrium and ovarian clear cell adenocarcinoma. Our observations suggest that the neoplastic cells of clear cell adenocarcinoma share the cellular properties of endometrial cells during pregnancy.

For surgical pathologists, histological distinction between ovarian yolk sac tumor and clear cell adenocarcinoma is often challenging, especially in cases in which the tumors are present in young 
adults and perimenopausal women. ${ }^{9}$ Among the variety of histological patterns of ovarian yolk sac tumors, glandular, papillary, and hepatoid patterns closely resemble clear cell adenocarcinomas. Many immunohistochemical markers, including CD15, $\alpha$-fetoprotein, and cytokeratin 7 , have been tested in the differential diagnoses of yolk sac tumor and clear cell adenocarcinoma. ${ }^{35,36}$ However, all these

Table 4 Correlation of GPC3 expression with clinical characteristics in ovarian clear cell carcinomas

\begin{tabular}{|c|c|c|c|}
\hline \multirow[t]{2}{*}{ Clinical characteristics } & \multicolumn{2}{|c|}{ Glypican-3 } & \multirow[t]{2}{*}{$\mathrm{P}$} \\
\hline & Positive & Negative & \\
\hline \multicolumn{4}{|l|}{ Age $(\mathrm{n}=94)$} \\
\hline$\leq 50$ & $29(50 \%)$ & $29(50 \%)$ & \\
\hline$>50$ & $12(33 \%)$ & $24(67 \%)$ & 0.11 \\
\hline \multicolumn{4}{|l|}{ Stage $(\mathrm{n}=68)$} \\
\hline I/II & $22(46 \%)$ & $26(54 \%)$ & \\
\hline III/IV & $8(40 \%)$ & $12(60 \%)$ & 0.66 \\
\hline \multicolumn{4}{|c|}{ Ovarian bilateralness $(\mathrm{n}=76)$} \\
\hline Unilateral & $30(47 \%)$ & $34(53 \%)$ & \\
\hline Bilateral & $3(25 \%)$ & $9(75 \%)$ & 0.16 \\
\hline \multicolumn{4}{|c|}{ Peritoneal dissemination $(\mathrm{n}=83)$} \\
\hline Negative & $31(44 \%)$ & $39(56 \%)$ & \\
\hline Positive & $7(54 \%)$ & $6(46 \%)$ & 0.40 \\
\hline \multicolumn{4}{|c|}{ Lymph node metastasis $(\mathrm{n}=73)$} \\
\hline Negative & $27(47 \%)$ & $31(53 \%)$ & \\
\hline Positive & $5(33 \%)$ & $10(66 \%)$ & 0.36 \\
\hline \multicolumn{4}{|l|}{ Survival status $(\mathrm{n}=94)$} \\
\hline Alive & $35(45 \%)$ & $42(55 \%)$ & \\
\hline Dead & $6(35 \%)$ & $11(65 \%)$ & 0.59 \\
\hline
\end{tabular}

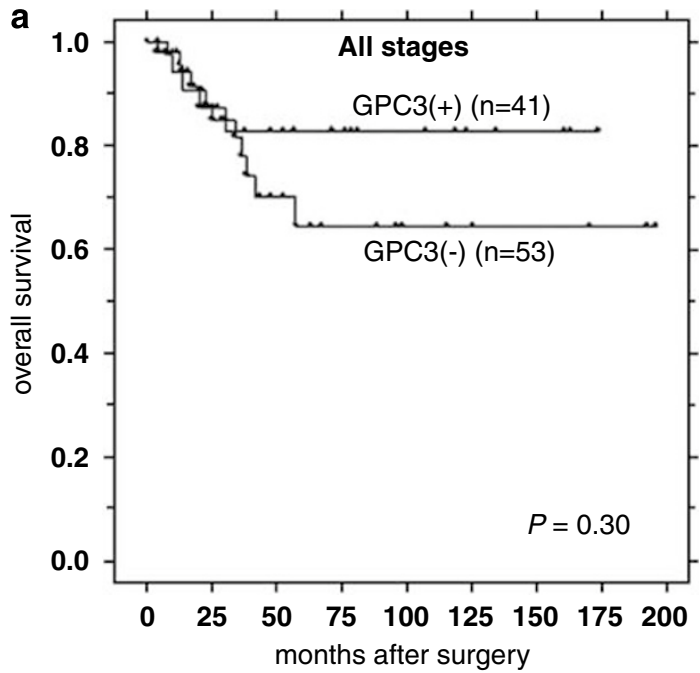

markers have problems associated with sensitivity and specificity. ${ }^{32,35-37}$ Recently, GPC3 has been reported to be overexpressed in testicular and ovarian yolk sac tumors. ${ }^{25,26,32}$ Esheba et al reported that GPC3 immunohistochemistry is useful for distinguishing ovarian yolk sac tumors from clear cell adenocarcinomas because of the higher GPC3 expression in ovarian yolk sac tumors compared to clear cell adenocarcinomas. ${ }^{32}$ Our results are similar to theirs in that most of yolk sac tumors showed diffuse GPC3 positivity, whereas only $10 \%$ of clear cell adenocarcinomas showed diffuse GPC3 positivity. Note, however, that focal or moderate $(1+$ or $2+)$

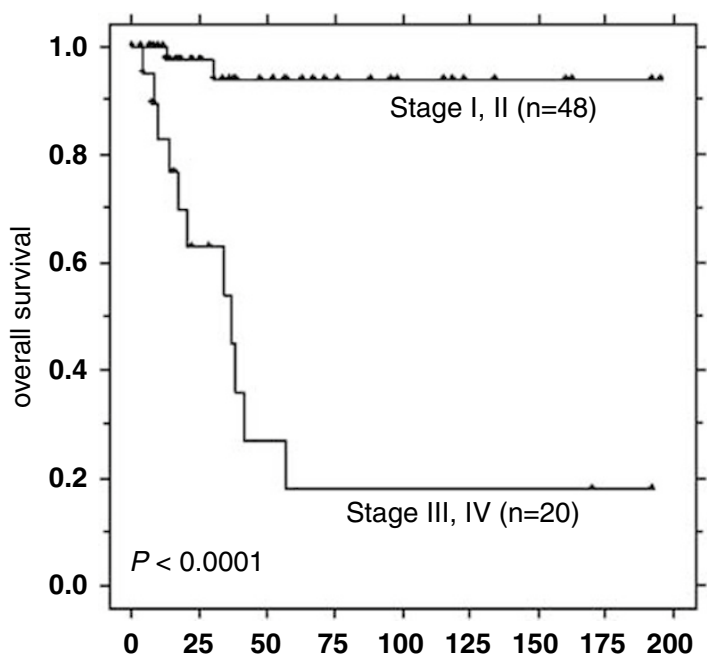

Figure 4 Kaplan-Meier survival curve for the impact of tumor stage (I/II vs III/IV) on ovarian clear cell adenocarcinoma. Patients with stage III/IV ovarian clear cell adenocarcinoma had a significantly poorer overall survival rate than those with stage I/II ovarian clear cell adenocarcinoma $(P<0.0001)$.

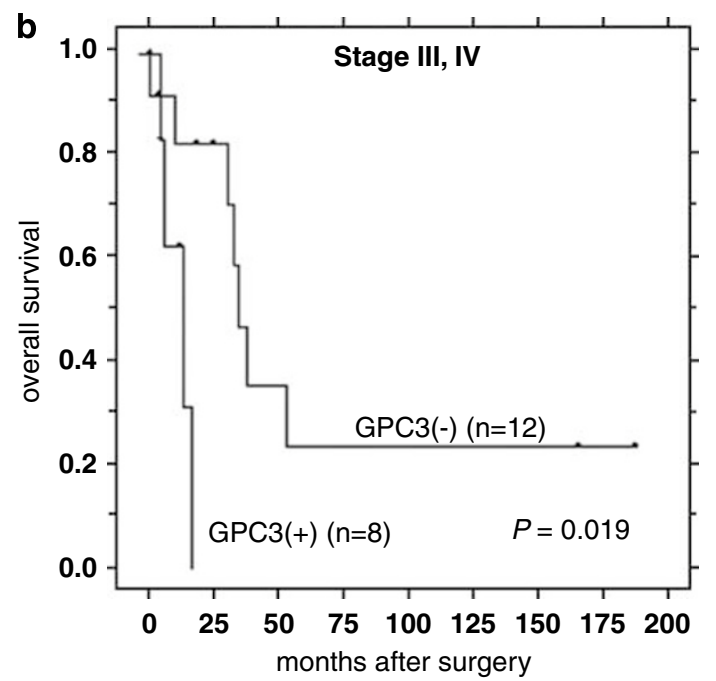

Figure 5 Survival analysis of ovarian clear cell adenocarcinoma cases in correlation with GPC3 expression. (a) Relationship between overall survival and GPC3 positivity in 94 ovarian clear cell adenocarcinoma cases. No significant difference was observed between overall survival of GPC3-positive and -negative cases $(P=0.30)$. (b) Relationship between overall survival and GPC3 positivity in stage III/IV ovarian clear cell adenocarcinoma $(n=20)$. In advanced stage ovarian clear cell adenocarcinoma cases, prognoses of GPC3-positive cases were significantly poorer than those of GPC3-negative cases $(P=0.019)$. 
GPC3 expression was observed frequently (34\%) in our clear cell adenocarcinoma cases. Therefore, a careful approach is recommended when interpreting GPC3 immunoreactivity in ovarian tumors, and GPC3 immunostaining should be used in combination with other markers when the histological distinction between yolk sac tumor and clear cell adenocarcinoma is difficult.

In this study, clinicopathological analyses of clear cell adenocarcinoma indicated that GPC3 expression was associated with significantly poor overall survival of the patients in stage III/IV $(P=0.0019)$, although the number of stage III/IV patients was relatively small. In general, the prognosis of patients with clear cell adenocarcinoma is poor, which is largely due to a low response rate to conventional platinum- or taxane-based chemotherapy. ${ }^{5,12,14}$ In a large retrospective study comparing 101 cases of clear cell adenocarcinoma and 235 cases of serous adenocarcinoma, Sugiyama et $a l^{5}$ showed that survival rates of stage III clear cell adenocarcinoma patients were significantly lower than those of stage III serous adenocarcinoma patients. In their study, the response rate to platinum-based chemotherapy in patients with clear cell adenocarcinoma was significantly lower than that in patients with serous adenocarcinoma. Currently, little is known about the role GPC3 plays in chemoresistance. Our results suggest the need to investigate the possible link between GPC3 expression and the chemoresistant nature of ovarian clear cell adenocarcinoma.

In conclusion, we found that GPC3 was overexpressed in clear cell adenocarcinoma of the ovary, but only rarely in other histological subtypes of ovarian epithelial carcinoma. In addition, we revealed that GPC3 expression was associated with poor prognosis in advanced stage clear cell adenocarcinoma cases. Further studies of the molecular function of GPC3 in the development and progression of ovarian clear cell adenocarcinoma are awaited.

\section{Acknowledgement}

This work was supported by the program for the Promotion of Fundamental Studies in Health Sciences of the National Sciences of the National Institute of Biomedical Innovation (NIBIO).

\section{Conflict of interest}

None declared.

\section{References}

1 Itamochi H, Kigawa J, Terakawa N. Mechanisms of chemoresistance and poor prognosis in ovarian clear cell carcinoma. Cancer Sci 2008;99:653-658.

2 Ishikura H, Teshima S, editor Atlas of Ovarian Tumor Pathology. Bunkodo Inc.: Tokyo, 2004, pp 9-12.
3 Stigliano I, Puricelli L, Filmus J, et al. Glypican-3 regulates migration, adhesion and actin cytoskeleton organization in mammary tumor cells through Wnt signaling modulation. Breast Cancer Res Treat 2009;114:251-262.

4 Itamochi H, Kigawa J, Sugiyama T, et al. Low proliferation activity may be associated with chemoresistance in clear cell carcinoma of the ovary. Obstet Gynecol 2002;100:281-287.

5 Sugiyama T, Kamura T, Kigawa J, et al. Clinical characteristics of clear cell carcinoma of the ovary: a distinct histologic type with poor prognosis and resistance to platinum-based chemotherapy. Cancer 2000;88:2584-2589.

6 McGuire V, Jesser CA, Whittemore AS. Survival among U.S. women with invasive epithelial ovarian cancer. Gynecol Oncol 2002;84:399-403.

7 Tavassoli FA, Devilee P, (eds) Pathology and Genetics of Tumours of the Breast and Female Genital Organs. IARC Press: Lyon, 2003, pp 114-139.

8 Scully RE, Young RH, Philip B, et al. (eds) Tumors of the ovary, maldeveloped gonads, fallopian tube, and broad ligament: AFIP Atlas of tumor pathology, Third series, fasicle 23. American registry of pathology: Washington DC, 1999, pp 141-151.

9 Ulbright TM. Germ cell tumors of the gonads: a selective review emphasizing problems in differential diagnosis, newly appreciated, and controversial issues. Mod Pathol 2005; (Suppl 2):S61-S79.

10 Scully RE, Barlow JF. 'Mesonephroma' of ovary. Tumor of Mullerian nature related to the endometrioid carcinoma. Cancer 1967;20:1405-1417.

11 Kennedy AW, Biscotti CV, Hart WR, et al. Ovarian clear cell adenocarcinoma. Gynecol Oncol 1989;32:342-349.

12 Goff BA, Sainz de la Cuesta R, Muntz HG, et al. Clear cell carcinoma of the ovary: a distinct histologic type with poor prognosis and resistance to platinum-based chemotherapy in stage III disease. Gynecol Oncol 1996;60:412-417.

13 Ogawa S, Kaku T, Amada S, et al. Ovarian endometriosis associated with ovarian carcinoma: a clinicopathological and immunohistochemical study. Gynecol Oncol 2000;77:298-304.

14 Takano M, Kikuchi Y, Yaegashi N, et al. Clear cell carcinoma of the ovary: a retrospective multicentre experience of 254 patients with complete surgical staging. Br J Cancer 2006;94:1369-1374.

15 Filmus J, Selleck SB. Glypicans: proteoglycans with a surprise. J Clin Invest 2001;108:497-501.

16 Grisaru S, Cano-Gauci D, Tee J, et al. Glypican-3 modulates BMP- and FGF-mediated effects during renal branching morphogenesis. Dev Biol 2001;231: 31-46.

17 De Cat B, Muyldermans SY, Coomans C, et al. Processing by proprotein convertases is required for glypican-3 modulation of cell survival, Wnt signaling, and gastrulation movements. J Cell Biol 2003;163: 625-635.

18 Midorikawa Y, Ishikawa S, Iwanari H, et al. Glypican3 , overexpressed in hepatocellular carcinoma, modulates FGF2 and BMP-7 signaling. Int J Cancer 2003;103:455-465.

19 Pellegrini M, Pilia G, Pantano S, et al. Gpc3 expression correlates with the phenotype of the Simpson-GolabiBehmel syndrome. Dev Dyn 1998;213:431-439.

20 Baumhoer D, Tornillo L, Stadlmann S, et al. Glypican 3 expression in human nonneoplastic, preneoplastic, 
and neoplastic tissues: a tissue microarray analysis of 4,387 tissue samples. Am J Clin Pathol 2008; 129:899-906.

21 Capurro M, Wanless IR, Sherman M, et al. Glypican-3: a novel serum and histochemical marker for hepatocellular carcinoma. Gastroenterology 2003;125:89-97.

22 Yamauchi N, Watanabe A, Hishinuma $\mathrm{M}$, et al. The glypican 3 oncofetal protein is a promising diagnostic marker for hepatocellular carcinoma. Mod Pathol 2005;18:1591-1598.

23 Nakatsura T, Kageshita T, Ito S, et al. Identification of glypican-3 as a novel tumor marker for melanoma. Clin Cancer Res 2004;10:6612-6621.

24 Aviel-Ronen S, Lau SK, Pintilie M, et al. Glypican-3 is overexpressed in lung squamous cell carcinoma, but not in adenocarcinoma. Mod Pathol 2008;21:817-825.

25 Ota S, Hishinuma M, Yamauchi N, et al. Oncofetal protein glypican-3 in testicular germ-cell tumor. Virchows Arch 2006;449:308-314.

26 Zynger DL, Dimov ND, Luan C, et al. Glypican 3: a novel marker in testicular germ cell tumors. Am J Surg Pathol 2006;30:1570-1575.

27 Hippo Y, Watanabe K, Watanabe A, et al. Identification of soluble NH2-terminal fragment of glypican-3 as a serological marker for early-stage hepatocellular carcinoma. Cancer Res 2004;64:2418-2423.

28 Motomura Y, Senju S, Nakatsura T, et al. Embryonic stem cell-derived dendritic cells expressing glypican3 , a recently identified oncofetal antigen, induce protective immunity against highly metastatic mouse melanoma, B16-F10. Cancer Res 2006;66:2414-2422.

29 Komori H, Nakatsura T, Senju S, et al. Identification of HLA-A2- or HLA-A24-restricted CTL epitopes possibly useful for glypican-3-specific immunotherapy of hepatocellular carcinoma. Clin Cancer Res 2006;12: 2689-2697.

30 Ishiguro T, Sugimoto M, Kinoshita Y, et al. Antiglypican 3 antibody as a potential antitumor agent for human liver cancer. Cancer Res 2008;68:9832-9838.

31 Stadlmann S, Gueth U, Baumhoer D, et al. Glypican-3 expression in primary and recurrent ovarian carcinomas. Int J Gynecol Pathol 2007;26:341-344.

32 Esheba GE, Pate LL, Longacre TA. Oncofetal protein glypican-3 distinguishes yolk sac tumor from clear cell carcinoma of the ovary. Am J Surg Pathol 2008; 32:600-607.

33 Seidman JD, Russell P, Kurman RJ. Surface epithelial tumors of the ovary. In: Kurman RJ (ed). Blaustein's Pathology of the Female Genital Tract, 5th edn. Springer: New York, 2002, pp 873-878.

34 Yamamoto S, Tsuda H, Aida S, et al. Immunohistochemical detection of hepatocyte nuclear factor 1 beta in ovarian and endometrial clear-cell adenocarcinomas and nonneoplastic endometrium. Hum Pathol 2007;38:1074-1080.

35 Ramalingam P, Malpica A, Silva EG, et al. The use of cytokeratin 7 and EMA in differentiating ovarian yolk sac tumors from endometrioid and clear cell carcinomas. Am J Surg Pathol 2004;28:1499-1505.

36 Zirker TA, Silva EG, Morris M, et al. Immunohistochemical differentiation of clear-cell carcinoma of the female genital tract and endodermal sinus tumor with the use of alpha-fetoprotein and Leu-M1. Am J Clin Pathol 1989;91:511-514.

37 Devouassoux-Shisheboran M, Schammel DP, Tavassoli FA. Ovarian hepatoid yolk sac tumours: morphological, immunohistochemical and ultrastructural features. Histopathology 1999;34:462-469. 